\title{
6
}

\section{ULTRANEOLIBERALISMO E FUNDO PÚBLICO: ANÁLISE DO ORÇAMENTO DAS POLÍTICAS SOCIAIS E DO AJUSTE FISCAL EM TEMPOS DE PANDEMIA*}

\author{
Elaine Rossetti Bebring \\ Giselle Soura
}

\section{INTRODUÇÃO}

O processo de ajuste fiscal vivenciado no Brasil desde os anos 1990 ganhou novos contornos ao longo do novo século e em nossos dias resulta na mais alta expropriação do fundo público com graves consequências para a classe trabalhadora. O presente texto procura desvelar estes processos e tem origem nos estudos acerca do fundo público e do financiamento das políticas sociais do Grupo de Estudos e Pesquisas do Orçamento Público e da Seguridade Social (GOPSS/UERJ) em articulação com o projeto de pesquisa Fundo Público e Estado no Brasil Contemporâneo (FUPEB/NUTSS/UNIRIO), ambos da área de Serviço Social, coordenados pelas autoras.

Iniciaremos o debate da caracterização do neoliberalismo em sua fase atual, chamado de ultraneoliberalismo, e das contrarreformas implementadas nos últimos anos no Brasil. Partiremos para uma breve análise dos recursos executados das principais funções orçamentárias entre 2010 e 2019 com intuito de demonstrar empiricamente o atualíssimo desmonte das políticas sociais. Por fim, encerraremos com apontamentos considerados de suma relevância sobre os acontecimentos de 2020 em meio a pandemia de COVID-19 com reflexos no mundo do trabalho.

*DOI - 10.29388/978-65-86678-37-6-0=f.131-150 
Tais estudos sãos resultados do esforço coletivo em compreender o tempo presente tomando como base dados da realidade concreta a partir da perspectiva do materialismo histórico e dialético, reforçando, portanto, o importante papel do fundo público na produção do conhecimento. Desta forma, a universidade pública cumpre seu papel de trazer a público reflexões imprescindíveis para compreender os desconcertantes processos que desafiam a construção do futuro.

\section{DO NEOLIBERALISMO E AO ULTRANEOLIBERALISMO: O APROFUNDAMENTO DO AJUSTE FISCAL}

As últimas décadas da história brasileira foram marcadas por uma tensa convivência entre os instrumentos legais oriundos da redemocratização brasileira e das lutas sociais que ali foram travadas - a exemplo da Constituição Federal de 1988 e seus capítulos sobre os direitos sociais e a Seguridade Social - e a orientação macroeconômica neoliberal e que hoje ganha contornos dramáticos com o ultraneoliberalismo, numa espécie de ajuste fiscal permanente (BEHRING, 2019). As injunções políticas da correlação de forças entre as classes e seus segmentos forjaram/atuaram nessa tensão. Mas os principais interessados, a classe trabalhadora, não foram capazes de reverter o ambiente de contrarreformas (BEHRING, 2003) instaurado imediatamente após a aprovação da Constituição de 1988, mesmo durante as gestões de centro-esquerda do Estado brasileiro. Assim, preponderou a lógica da punção do fundo público sob a regência das instituições financeiras nacionais e internacionais, credoras da dívida pública, por meio de uma macroeconomia engenhosa, inaugurada pelo Plano Real e aprofundada pelo acordo com o FMI (1998). Uma lógica orientada para a preservação de parcelas ainda maiores do butim - a mais-valia socialmente produzida - para a finança, sustentada sobremaneira pelo fundo público que é também e cada vez mais formado com recursos de reprodução da classe trabalhadora, o trabalho necessário, operando desse modo uma transferência "de baixo para cima". Esta lógica orientadora do ajuste radicalizou-se no chamado Novo Regime Fiscal, o que configura o ultraneoliberalismo. Vejamos de forma sintética o curso desse processo. 
Desde abril de 2016, acompanhamos os desdobramentos do golpe de Estado de novo tipo em andamento no Brasil, e que criaram as condições para o ascenso da extrema direita nas eleições de 2018. Numa articulação envolvendo segmentos de todos os poderes da república e da sociedade civil com destaque para a grande mídia, forjou-se a chegada à presidência do Vice-Presidente Michel Temer (MDB). De novo Eldorado latino-americano que debelou a miséria e alçou milhões à "classe média", a partir da implementação de um projeto "neodesenvolvimentista" que teria rompido com o neoliberalismo, conduzido pelo PT e aliados, em menos de quatro anos adentramos numa espécie de barbárie ultraneoliberal. Dessa vez, conduzida com apoio da finança e do grande capital, por segmentos da velha política brasileira ligados a dutos de corrupção e do crime organizado, o que vai se aprofundar em 2019 com a chegada ao poder de Bolsonaro, Paulo Guedes e se seus Chicago boys. O fato é que em meio às oscilações políticas e de gestão macroeconômica - deslocamentos que tem relação com as coalizões de classe e blocos de poder que se forjaram desde a redemocratização do país, bem como com a vulnerabilidade externa e posição do país na economia mundial - houve uma forte persistência do neoliberalismo e de suas políticas de ajuste fiscal, as quais atingem de forma deletéria a política social em seu financiamento e concepção.

O neoliberalismo, na pista de Dardot e Laval (2016), é uma espécie de razão do mundo à qual os projetos político-econômicos em curso estiveram submetidos. Esta resposta burguesa se conectou visceralmente com as contradições geradas pela profunda e estrutural crise do capitalismo em curso desde o início dos anos setenta do século XX, quando se abre uma onda longa com tonalidade de estagnação (MANDEL, [1972]1982). Suas diferentes manifestações oscilaram ao longo do tempo, como a crise das subprimes de 2008/2009 e a profunda crise atual conectada ao catalisador da pandemia, e períodos curtos de certa bonança, a exemplo do início dos anos 90, mas dentro de um quadro geral recessivo. O neoliberalismo é, desta forma, o corolário da reação burguesa

\footnotetext{
${ }^{1}$ Os governos do PT e intelectuais a eles vinculados se auto declararam neodesenvolvimentistas, termo que aqui utilizamos entre aspas, pois mesmo com alguns deslocamentos em relação ao período anterior, não consideramos que a alusão tenha correspondência com a realidade, dado que não foram superadas as restrições do ajuste fiscal em curso.
} 
à sua própria crise e que tem como eixo central uma forte ofensiva sobre o trabalho, tendo em vista a extração do mais valor em condições ótimas ao redor do mundo, em especial nos países dependentes, em busca do diferencial de produtividade do trabalho (MANDEL, [1972]1982), e onde a regra é a superexploração da força de trabalho (MARINI, 1973; LUCE, 2018; MATTOS, 2020). A reconstituição da superpopulação relativa e alteração das condições de oferta da força de trabalho com as expropriações daí decorrentes (BOSCHETTI et al., 2018; FONTES, 2010) se tornam elementos vitais para a recuperação das taxas de lucro e realocação do fundo público, sendo as medidas de ajuste e contrarreformas estratégicas nessa direção.

Os acontecimentos precipitaram-se na direção do ultraneoliberalismo a partir de maio de 2016 (CISLAGHI, 2020), desencadeados com a posse de Michel Temer, cujo projeto estava expresso no documento de seu partido, o MDB, intitulado Uma Ponte para o Futuro, lançado em outubro de 2015, o que já sinalizava as articulações para o Golpe. Ali se nota claramente a presença das linhas mestras do Plano Diretor da Reforma do Estado (PDRE, 1995), um documento orientador do período pós Real, e se abre o terceiro momento de nítido aprofundamento do neoliberalismo no Brasil, com o Novo Regime Fiscal ultraneoliberal. Este é o período no qual nos encontramos, mas agora com requintes de crueldade, já que desde as eleições de 2018 - fortemente viciadas pela perseguição de adversários, a exemplo da prisão do ex Presidente Lula (2003 2010), e pela difusão de fake news em massa - o país está sob a condução de um governo neofascista (BEHRING, 2019; MAT'TOS, 2020).

Algumas das medidas mais representativas do projeto em curso desde 2016 ganharam contornos dramáticos com esta combinação entre ultraneoliberalismo e neofascismo. A medida abre-alas do Novo Regime Fiscal foi a Emenda Constitucional 95 (EC 95), aprovada sob forte repressão em Brasília, em 2016. O discurso da EC 95 foi o de realizar sacrifícios para entregar um país saneado e que voltasse a crescer, responsabilizando os gastos públicos, sobretudo com direitos trabalhistas e previdenciários, como sempre. Assim, tornou-se constitucional a correção dos gastos primários pela inflação do ano anterior, por vinte anos. Apesar de a dívida brasileira ter chegado em 2016 a 4,2 trilhões e a relação 
dívida/PIB estivesse em 70,1\%, é preciso comparar com outros países para justificar a necessidade de uma medida tão destrutiva - e intocável, como declaram todos os dias representantes do atual governo. Com dados de 2016 tem-se: a dos EUA, 101\%; da zona euro, de cerca de 90,7 \%; do Japão, de 229,2\%. O país não estava quebrado como chantageavam os defensores dessa medida e do Golpe. Ademais, Dilma (2011 2015) já vinha realizando um duro ajuste fiscal no fim de seu primeiro mandato e em 2015, com medidas relacionadas ao seguro-desemprego e pensões, sem crescimento no gasto com pessoal e no gasto social, e com contração no investimento, o que tornou comum se falar em "estelionato eleitoral" nas eleições de 2014.

Qual a razão deste enrijecimento do Estado, especialmente do Estado Social, num prazo tão amplo? Para a economista Laura Carvalho (2016), a EC 95 não tem relação com uma ameaça de inflação, cujo leve impulso se deu com a liberação de preços administrados pelo Estado e não com o gasto público. Ela critica duramente o axioma de que o controle rígido do gasto público leva à mítica confiança ${ }^{2}$ e afirma que 22 países têm regras de gastos, mas em nenhum deles a regra é para 20 anos. Sobretudo, essas não são regras constitucionais. A EC 95, portanto, foi de um aventureirismo irresponsável inimaginável, já que independentemente do desempenho econômico, congela-se os gastos primários do orçamento público brasileiro, no mesmo passo em que se libera a apropriação do fundo público pelo capital portador de juros e pelos especuladores. Em caso de descumprimento da EC 95, estão previstas sanções. Aqui há uma conexão direta entre a EC 95 e a contrarreforma da previdência, pois uma dessas sanções é não poder elevar as despesas obrigatórias, o que atropela a recomposição do salário mínimo, indexadora de benefícios previdenciários e assistenciais, como o BPC. Temos, portanto, as razões da dura contrarreforma da previdência de Bolsonaro/Guedes, em 2019, dando sequência ao baile, na ironia de Demier (2017).

Se em 2016 o Brasil tinha 206 milhões de habitantes, dos quais 16,8 milhões estavam acima dos 65 anos, estima-se que em 2036, sere-

\footnotetext{
${ }^{2}$ De fato, isso não aconteceu com o duro ajuste de curto prazo de Dilma, que inclusive vetou a necessária e urgente Auditoria da Dívida, aumentou o superávit primário em 2011 e realizou corte monumental de gastos em 2014 e 2015.
} 
mos 227 milhões, dos quais 36 milhões acima dos 65 anos, segundo o Instituto Brasileiro de Economia e Estatística (IBGE). Ou seja, há um decréscimo relativo de jovens e um acréscimo na população idosa. Como conter os gastos obrigatórios nesse contexto de crescimento da população idosa? A forma foi o ataque frontal aos direitos de aposentadoria jogando milhões de trabalhadores(as) na pobreza pela dificuldade de cumprir com os requisitos de idade e contribuição. E o ataque veio também por meio da Emenda Constitucional 93 que elevou a Desvinculação de Receitas da União (DRU) à 30\% de desvinculação de impostos e contribuições, drenando mais recursos, e a prorrogou para 2023, o que mostra mais uma vez seu lugar central na sustentação da economia política do período da redemocratização, do ajuste fiscal permanente. Postos esses parâmetros mais gerais, vejamos o comportamento da formação e alocação do fundo público, via orçamento público entre 2010 e 2019, além de alguns apontamentos sobre este trágico ano de 2020.

\section{ORÇAMENTO PÚBLICO E POLÍTICAS SOCIAIS (2010-2019)}

Vimos que o cenário político-econômico no qual se encontra a sociedade brasileira, reflexo das requisições do grande capital global em tempos de crise aguda, traz mudanças significativas e de grande impacto social na atuação do Estado, em especial, sua função no que se refere a reprodução social da força de trabalho. $\mathrm{O}$ ajuste fiscal permanente tem sido implementado com objetivo de expropriar parcelas exponenciais do fundo público para a valorização direta e indireta do capital portador de juros.

Tentaremos aqui apresentar como esse processo se evidencia no campo das políticas sociais trazendo alguns dados gerais do orçamento das principais funções relativas à garantia de direitos sociais nos últimos dez anos, ou seja, do ano de 2010 a 2019. Nesse breve levantamento buscaremos demonstrar a redução absoluta e/ou relativa dos recursos nos tempos atuais e o caráter assumido pelo fundo público no Brasil ${ }^{3}$. As

\footnotetext{
${ }^{3}$ Nossa análise utilizou as fontes primárias de acesso ao Orçamento Geral da União, como a plataforma Siga Brasil e o Banco de Dados Access. O recorte temporal foi de 2010 a 2019 (ou seja, execução de 10 anos) e os valores pagos ou autorizados para 2020. No âmbito das fontes orçamentárias o recorte temporal levantou dados de 2015 a 2019 para apresentar as principais fontes
} 
funções por nós elencadas para levantamento de dados foram as relativas à Seguridade Social (saúde, previdência e assistência social), educação e outras funções que podem ser relacionadas à políticas que garantem direitos sociais, como cultura, habitação, direitos de cidadania e saneamento, e também mapeamos brevemente os gastos com as funções de ciência e tecnologia e trabalho ${ }^{4}$.

Os dados nos mostram que a Seguridade Social de 2010 a 2019 apresenta um crescimento vegetativo, em especial a saúde e a assistência social. A previdência, por seu lado, apresenta aumento em razão do reajuste do salário mínimo.

Gráfico 1 - Valores pagos Seguridade e Educação (em reais)

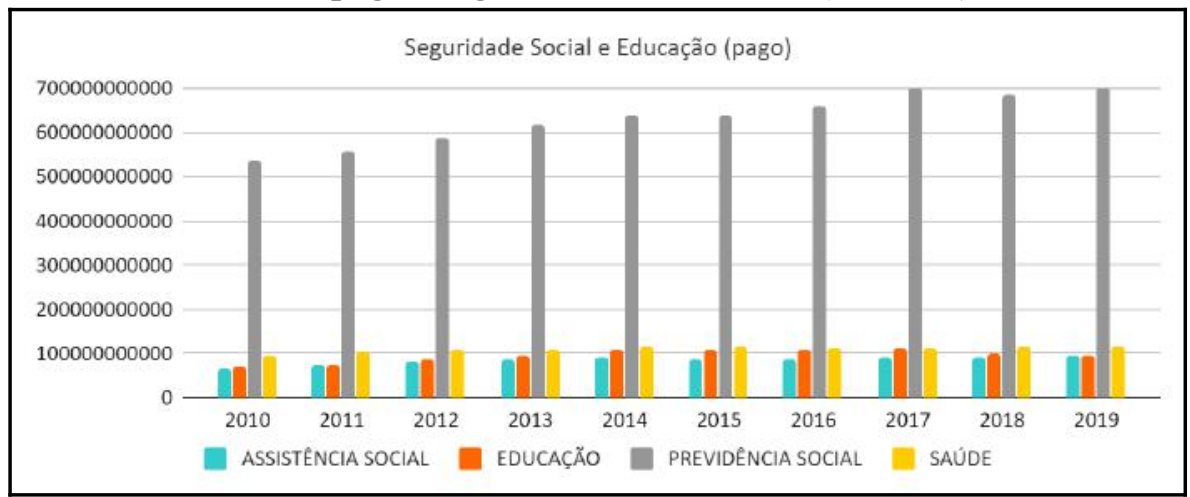

Fonte: Siga Brasil. Elaboração própria

Embora os recursos apresentem elevação, consideramos o crescimento vegetativo em função de estar situado abaixo da inflação acumulada nos anos em questão, que correspondeu ao total de 59\%, enquanto o maior aumento entre os últimos 10 anos foi da assistência social, em torno de 43\%, ainda assim 16 pontos percentuais abaixo da inflação no mesmo período. A saúde sofreu uma redução ainda maior se comparada à inflação. E neste caso falamos de uma política essencialmente universal e indispensável à classe trabalhadora mais pobre.

que financiaram algumas políticas sociais.

${ }^{4}$ Os dados ora apresentados correspondem a valores pagos. Em alguns momentos apresentaremos os valores pagos juntamente ao executado até setembro de 2020 e valores autorizados pela Lei Orçamentária do ano correspondente. Todos os valores estão deflacionados pelo IPCA. 
Tabela 1 - Variação percentual 2019/2010

\begin{tabular}{|l|r|}
\hline & $\%$ percentual $2010-2019$ \\
\hline ASSISTÊNCIA SOCIAL & $43 \%$ \\
\hline EDUCAÇÃO & $39 \%$ \\
\hline PREVIDÉNCIA SOCIAL & $31 \%$ \\
\hline SAÚDE & $23 \%$ \\
\hline INFLAÇÃO ACUMULADA & $59 \%$ \\
\hline
\end{tabular}

Fonte: Siga Brasil. Elaboração própria

Ainda sobre os dados da Seguridade e Educação, excluindo a previdência, vemos no gráfico 2 a estagnação dos recursos a partir de 2016 e 2017, efeitos da crise e das políticas de ajuste fiscal, como DRU e EC 95, anteriormente citadas. No caso da educação vemos a queda dos recursos comparados à ascensão demonstrada entre 2010 e 2014. Em 2019 retomamos os patamares de recursos de 2013, embora a inflação acumulada desse período até hoje tenha sido de mais de 40\%. Na prática significa a perda relativa dos recursos para educação.

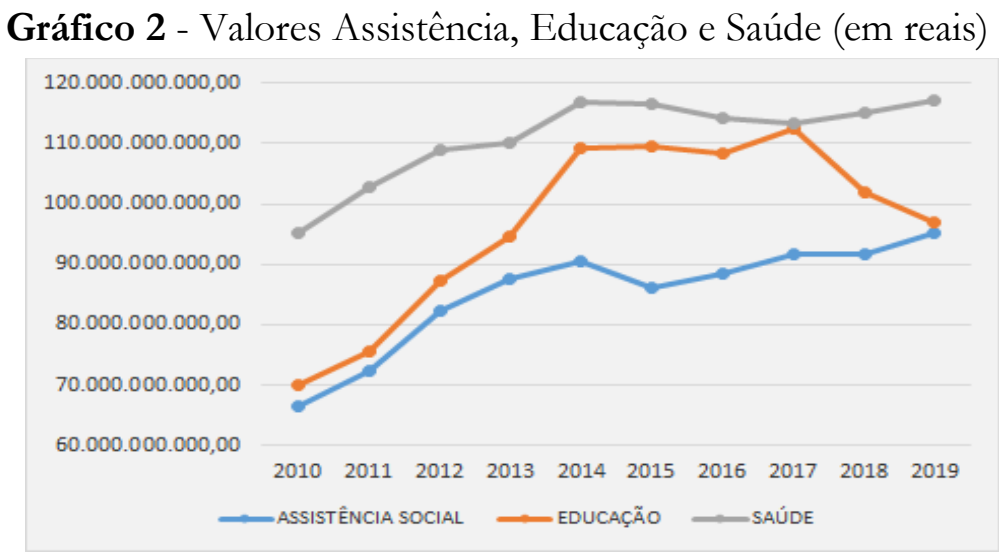

Fonte: Siga Brasil. Elaboração própria

Tomando essa política como referência, notamos que entre o valor autorizado para 2020 (LOA) e 2019 houve uma redução de mais de 14 bilhões de reais, sendo a maior perda na educação superior, correspondendo a uma queda de $12 \%$. Sem dúvida é a política mais atacada nos últimos anos. Identificamos ainda, em 2020, um contingenciamento de $\mathrm{R} \$ 4,8$ bilhões na função Educação, sendo R $\$ 2,2$ bilhões do Ensino 
Superior. Temos assim, uma deliberada política de estrangulamento da educação no país, coerente com a ideia difundida desde 2016 para a população, agravada pela guerra cultural neofascista: "não pense, trabalhe".

Tabela 2 - Valores autorizados para Educação (LOA 2019 e 2020)

\begin{tabular}{|l|r|}
\hline EDUCAÇÃO & \\
\hline 2019 & $123.871 .583 .719,00$ \\
\hline 2020 & $109.392 .768 .662,26$ \\
\hline Variação nominal & $-14.478 .815 .056,74$ \\
\hline Variação percentual & $-12 \%$ \\
\hline
\end{tabular}

Fonte: Siga Brasil. Elaboração própria

Já a função saúde apresentou uma elevação em valores reais, mas uma queda significativa em relação ao \% do PIB. Como vemos, os valores a partir de 2013 ficam abaixo de 1\% (gráfico 3). Dentre as principais fontes de arrecadação para saúde, a Cofins e CSLL apresentaram uma queda nos últimos anos. Tais fontes foram criadas pela Constituição de 1988 e, apesar de consideradas regressivas (SALVADOR, 2010), tornaram-se importantes para manutenção da Seguridade Social. Assim, não é surpreendente que o Sistema Único de Saúde tenha dificuldades crônicas e ainda mais agravadas no contexto da pandemia de 2020 .

\section{Gráfico 3 - Saúde - \% PIB}

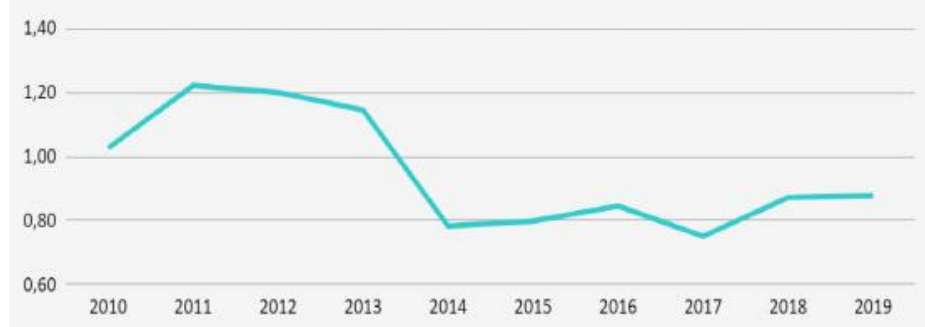

Fonte: Siga Brasil. Elaboração própria

A política de assistência social é a única dentre todas do orçamento que apresenta uma elevação sistemática. Fica clara a perspectiva dos últimos governos em substituir o já débil aparato estatal e normativo 
de políticas sociais abrangentes, não contributivas e não condicionadas por transferências monetárias com condicionalidades (BEHRING; BOSCHETTI, 2020). O processo de financeirização e monetarização das políticas sociais têm na assistência social um dos seus pilares fundamentais, no qual os recursos que deveriam ser exclusivamente destinados aos trabalhadores mais aviltados de acesso aos bens e serviços são utilizados para alimentar o rentismo (SOUZA, 2012).

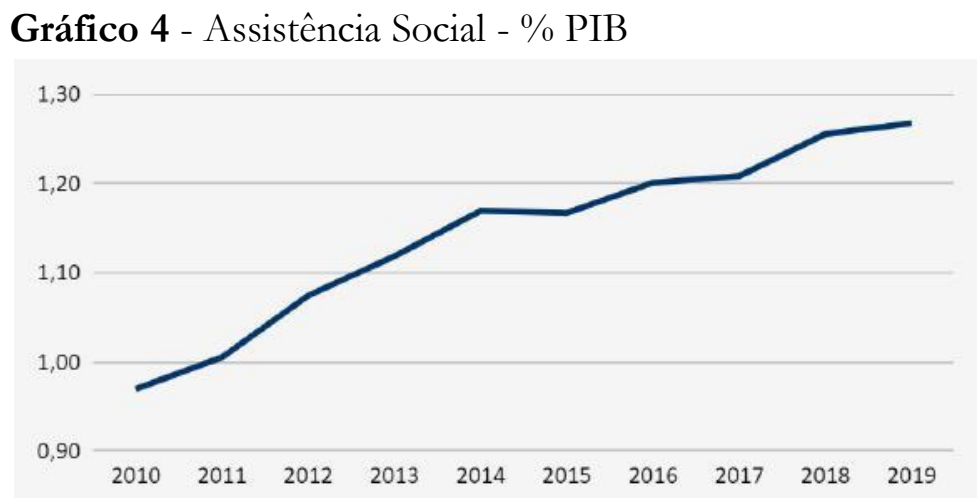

Fonte: Siga Brasil. Elaboração própria

Os recursos destinados à totalidade previdência se aproximam dos gastos com serviços da dívida pública interna (juros e encargos), como ocorrido no ano de 2012 em que a previdência executou mais de $\mathrm{R} \$ 588,2$ bilhões de reais e os juros sugaram mais de $\mathrm{R} \$ 540$ bilhões do orçamento. A dívida pública, portanto, caracteriza-se como o grande programa de transferência "de renda" das classes trabalhadoras para os super ricos, que correspondem a cerca de 15 mil famílias, dentre elas 206 bilionários recém revelados pela Revista Forbes. Dados de Salvador (BEHRING, 2020) mostram que entre 2010 e 2019, R \$ 5.412,96 trilhões foram pagos em juros e amortizações da dívida pública, o que em alguns anos (2012, por exemplo, ultrapassou a marca de 30\% do Orçamento Geral da União (OGU). Estes são indicadores de onde está a verdadeira gambiarra de recursos públicos para a qual se orienta o ajuste fiscal brasileiro. 
Ainda sobre a previdência, uma das principais fontes de financiamento em 2019 foram os títulos do Tesouro Nacional, ou seja, contração de dívida pública para financiar benefícios do INSS. Enquanto entre 2016 a 2018 os valores advindos dessa fonte estavam em torno de 50 bilhões, em 2019 eles saltam para 205 bilhões de reais, ampliando assim o endividamento e, consequentemente, a expropriação de recursos via contrarreformas para remunerar o rentismo.

Gráfico 5 - Demais funções da área social em reais (pago)

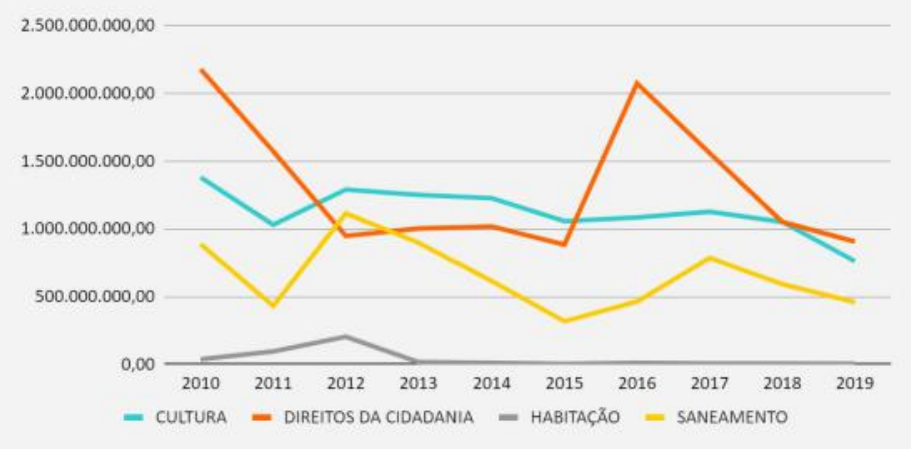

Fonte: Siga Brasil. Elaboração própria

Analisando outras funções (gráfico 5) importantes do orçamento, vemos uma brutal queda de recursos nas políticas de extrema importância para a classe trabalhadora. Os recursos da função direitos de cidadania foram os que sofreram a maior queda em termos reais, reduzindo seus gastos de mais de $\mathrm{R} \$ 2,1$ bilhões para $\mathrm{R} \$ 905$ milhões de reais. Os recursos da habitação, que chegou a executar $\mathrm{R} \$ 203,7$ milhões de reais em 2012 (reflexo ainda do programa Minha Casa, Minha Vida), em 2019 sobreviveu com apenas $\mathrm{R} \$ 9$ milhões.

Tabela 3 - Variação entre 2010 e 2019 por função (pago)

\begin{tabular}{|c|c|c|}
\hline Função & Variação em reais 2019-2010 & \% 2010-2019 \\
\hline ASSISTÊNCIA SOCIAL & $\mathrm{R} \$ 28.720 .873 .295,80$ & $43 \%$ \\
\hline CIÊNCIA E TECNOLOGIA & $-\mathrm{R} \$ 2.619 .754 .566,25$ & $-29 \%$ \\
\hline CULTURA & $-\mathrm{R} \$ 619.336 .420,77$ & $-45 \%$ \\
\hline DESPORTO E LAZER & $-\mathrm{R} \$ 275.900 .804,75$ & $-63 \%$ \\
\hline
\end{tabular}




\begin{tabular}{|c|c|c|}
\hline DIREITOS DA CIDADANIA & $-\mathrm{R} \$ 1.271 .325 .776,69$ & $-58 \%$ \\
\hline EDUCAÇÃO & $\mathrm{R} \$ 26.946 .834 .494,11$ & $39 \%$ \\
\hline HABITAÇÃO & $-\mathrm{R} \$ 31.614 .123,15$ & $-86 \%$ \\
\hline PREVIDÊNCIA SOCIAL & $\mathrm{R} \$ 164.505 .998 .849,21$ & $31 \%$ \\
\hline SANEAMENTO & $-\mathrm{R} \$ 428.741 .117,89$ & $-48 \%$ \\
\hline SAÚDE & $\mathrm{R} \$ 21.776 .838 .808,22$ & $23 \%$ \\
\hline TRABALHO & $\mathrm{R} \$ 21.113 .701 .602,40$ & $40 \%$ \\
\hline
\end{tabular}

Fonte: Siga Brasil. Elaboração própria

De todas as funções da área social, apenas assistência social, educação, saúde, previdência social e trabalho apresentaram alguma elevação nos últimos 10 anos, mas todas abaixo da inflação acumulada. Considerando o aumento da demanda, pelo crescimento da população e pelo desemprego e precarização da força de trabalho em curso, tal evolução não pode ser considerada como recomposição orçamentária.

Destacamos a vertiginosa queda de recursos das funções ciência e tecnologia e desporto e lazer (tabela 3). É importante sublinhar que um país que desfinancia a ciência, o que se combina ao decréscimo de recursos da educação, está condenando a soberania e o futuro, o que remete à condição de dependência do país. O mesmo se pode dizer da cultura, elemento central da constituição do ethos do país.

Gráfico 6 - Principais funções da área social (pago)

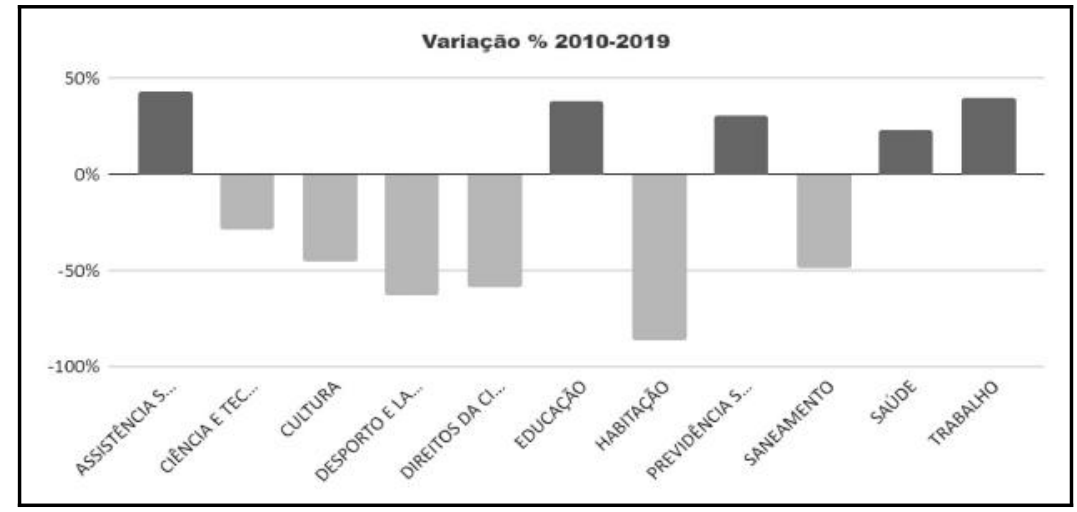

Fonte: Siga Brasil. Elaboração própria 


\section{PANDEMIA E A CONDIÇÃO DO GASTO SOCIAL NA ATUA- LIDADE: UMA CONCLUSÃO À QUENTE}

A pandemia de Covid-19 teve um encontro explosivo com o Brasil pós golpe de 2016. Mas, antes disso, a pandemia é uma espécie de catalisador de tendências de crise mundial do capitalismo que já estavam em andamento, apesar de não se limitar a essa característica. Husson (2020) nos mostra que o vírus, de fato, não atacou um “corpo são”, mas que é mais que um catalisador, já que a combinação entre crise sanitária e crise econômica sob o signo do confinamento dessincronizado é inédita e atinge desigualmente diferentes segmentos - a exemplo do setor de serviços intensivo em força de trabalho - e países. E a crise nestes termos pode se transformar em alimentar, obrigando a milhões de pessoas escolherem entre a fome ou a exposição ao vírus, destacadamente na periferia do capitalismo. Para o capital, em que pesem as perdas, a crise pode ser uma espécie de janela de oportunidades. Num primeiro momento em vários países os princípios neoliberais foram colocados em suspensão, com forte intervenção dos Estados para conter a propagação do vírus e seus efeitos econômicos, compensando os efeitos da pandemia. No entanto, para Husson, a seu tempo haverá uma ofensiva para retomar a taxa de mais valia e recuperar o tempo perdido, descarregando sobre a classe trabalhadora a enorme dívida que está sendo contraída, como o fizeram depois de 2008/2009, e retornando ao "business as usual", após uma ampla destruição de forças produtivas.

Neste passo, são abundantes os sinais de uma nova ofensiva sobre a força de trabalho, com forte automatização, precarização do trabalho, flexibilização de regras nos contratos de trabalho, rebaixamento de salários, entre outros, aprofundando a reestruturação produtiva. Por outro aspecto, a combinação paradoxal entre competição ofensiva e protecionismo defensivo tende a se instaurar na economia mundial refletindo as desiguais e dessincrônicas respostas à crise. Nesse sentido, o autor prevê uma amplificação das tensões entre Estados Unidos e China no próximo período. Outro elemento importante é a titularização da dívida pública assumida no contexto da pandemia que deverá gerar um retorno à austeridade. Assim, longe de ser um momento de revelação e de afasta- 
mento dos princípios neoliberais, a gestão burguesa da crise tende a retornar à ortodoxia, assim que as condições o permitam.

No caso brasileiro, o investimento de poder político no bloco de poder em torno de Jair Bolsonaro a partir de 2019, desencadeou uma ofensiva conservadora econômica, social e cultural. Porém, destacadamente do ponto de vista econômico, o que vínhamos acompanhando até antes da pandemia era um retumbante fracasso: mesmo com a contrarreforma do trabalho e da previdência não houve a prometida retomada econômica e nem crescimento de empregos formais, e 2019 fechou com um medíocre "pibinho" de 1,1\% e 11,6\% de desemprego, uma medíocre redução face aos $12,7 \%$ de 2017 , provocada tão somente pelo crescimento do trabalho sem carteira e por conta própria, resultado das contrarreformas. E, na sequência, a inflexão pandêmica se encontrou de forma explosiva com esse Brasil já dilacerado.

Já havia, portanto, um aumento da fratura da desigualdade social crônica. Mas com a pandemia e as medidas para seu suposto enfrentamento, aquela se tornou exposta. Houve a diminuição dos salários e da jornada de trabalho, diga-se, suspensão dos contratos sem demissão, e políticas de apoio às empresas por meio das Medidas Provisórias 927 e 936. Ainda assim, dados do IBGE revelam que, até junho de 2020, houve a extinção de 7,8 milhões de postos de trabalho e a solicitação de seguro-desemprego para 3,9 milhões de trabalhadores. Em julho, a taxa de desemprego chegou a $13,1 \%$ e 522 mil negócios suspenderam atividades ou fecharam definitivamente, comparado ao período anterior.

As medidas do governo revelaram-se frágeis e foram acompanhadas pelo auxílio emergencial - inicialmente proposto pelo governo no valor de $\mathrm{R} \$ 200$ e recomposto pelo Congresso em $\mathrm{R} \$ 600$ ao longo de cinco meses para usuários do Bolsa Família, inscritos no CadÚnico e trabalhadores informais inscritos no aplicativo da Caixa Econômica Federal. A imensa procura pelo auxílio, uma medida que se revelou fundamental, revelou aos desavisados o tamanho da desigualdade brasileira. Até julho de 2020, a Empresa de Tecnologia e Informações da Previdência (DATAPREV) analisou 108,4 milhões de cadastros, dos quais 64,1 milhões estão recebendo auxílio, incluindo os inscritos no Bolsa Família, 
a um custo de $\mathrm{R} \$ 90,8$ bilhões de reais ${ }^{5}$.

Um dado nos parece de extrema relevância sobre este programa de transferência monetária: ao analisarmos suas fontes de financiamento, vemos que $52 \%$ dos recursos advém de Títulos de Responsabilidade do Tesouro Nacional. Isto significa que o Auxílio Emergencial está sendo financiado com recursos da emissão de dívida. E quanto maior a contração e volume total da dívida, mais contrarreformas para reduzir gasto social. Deste modo o programa criado em meio a maior crise sanitária já vivenciada, para atenuar (sem grande sucesso) os efeitos deletérios da crise econômica dela decorrente, remunera direta e indiretamente o capital portador de juros, imediatamente (já que a Caixa ao operá-lo recebe para tal); e a médio e longo prazo, garante mais dívida e mais fundo público para seu pagamento.

Alimentando a crise social, temos a resposta econômica ultraneoliberal, instaurando a lógica do contador e do Estado asfixiado, e buscando socializar o custo da crise, a exemplo da ofensiva sobre o funcionalis mo público e dos anúncios de um pós-pandemia com novos impostos que estão longe da taxação das grandes fortunas e de fechar a gambiarra de fundo público por meio da dívida pública, o que confirma a análise de Husson sobre o business as usual pós pandemia ${ }^{6}$. Assim, tais custos, bem como o dos gastos com a calamidade pública de uma maneira geral, serão certamente repassados aos trabalhadores: fala-se do fim do abono salarial, do seguro defeso, e até do seguro-desemprego, todos direitos trabalhistas, e de uma contrarreforma tributária que compense o gasto com o novo programa, bem como de apropriação de recursos do Fundo de Desenvolvimento da Educação Básica (FUNDEB), o que mostra que este projeto aponta para uma sociedade de assistidos e não de educados.

\footnotetext{
${ }^{5}$ Chama atenção na conta o número de solicitações negadas, o que requisitaria uma investigação mais profunda sobre os fundamentos do bloqueio do acesso. Houve residuais tentativas de fraude no programa que foram amplamente divulgadas na imprensa, mas que não diminuem o impacto desses números e menos ainda das imagens das filas na frente das agências da Caixa Econômi ca Federal, que lamentavelmente se tornaram focos de propagação do vírus.

${ }^{6}$ Diante do impacto do auxílio emergencial, o governo fala de um novo programa de transferência de renda para chamar de seu, mais abrangente que o Bolsa Família, mas com valores mais reduzidos, e que tem sido chamado de Renda Cidadã, mas sem qualquer disposição política para revogar as ECs 93 (DRU) e 95 (teto de gastos).
} 
O chamado "orçamento de guerra" de 2020 ofertou a migalha de $\mathrm{R} \$ 13,8$ bilhões de reais para a saúde ao lado do lastro de $\mathrm{R} \$ 1,2$ trilhão para operações de crédito pelos bancos e abrindo a possibilidade de compra de títulos podres com recursos do tesouro nacional! Então, não estamos falando de guerra contra o vírus, mas de salvamento das empresas no contexto da crise. A saúde, o melhor exemplo nesta altura da nossa análise, já vinha sendo desfinanciada, mantendo-se num gasto percentual em torno de 1,73\% sobre o PIB, em 2015, e 1,74\% sobre o PIB, em 2019; e num gasto público total (União, Estados e Municípios) de 3,9\% sobre o PIB. Trata-se de um percentual irrisório e cobrou seu preço na pandemia, com falta de leitos, equipamentos e pessoal. Com a EC 95, a saúde foi a política que mais perdeu recursos, conforme já indicado nos dados anteriores e se revela também no estudo de Boschetti e Teixeira (2019) - uma perda de 9,9\% entre 2016 e 2018. Manteve-se no mesmo patamar em 2019 e, em 2020, há uma leve recomposição frente à crise sanitária (SIGA BRASIL, junho de 2020). Portanto, Guedes e equipe não dormiram neoliberais e acordaram neokeynesianos, reivindicando mais Estado. Quando passar o pior da pandemia, cobrarão a conta, provavelmente com mais um combo de horrores econômicos.

Outro elemento explosivo com o qual a pandemia se encontra no Brasil é o neofascismo genocida, que impulsiona uma atitude negacionista da ciência, e fatalista a respeito dos impactos de uma pandemia destrutiva como a Covid-19. Enquanto escrevemos essas linhas, ultrapassamos os 140 mil mortos ${ }^{7}$, fora as subnotificações, e temos quase 5 milhões de contaminados. Pela lógica neofascista, não importam vidas poupadas, mas sim o ciclo implacável D - M - D', a liberação da atividade econômica a qualquer custo. As projeções de pesquisadores da Fiocruz e da UFRJ, dentre outras instituições, eram de que caso o projeto de liberação total da atividade econômica prosperasse da forma proposta por Bolsonaro e seus asseclas, morreriam mais de um milhão de pessoas no Brasil. Não estamos diante de uma irracionalidade ou de uma feroz natureza humana adormecida. Estamos diante do fascismo do século XXI, o neofascismo, do qual as classes dominantes lançam mão para assegurar a

${ }^{7}$ Dados de setembro de 2020. 
propriedade privada e o lucro. Daí advém a indiferença: quem está morrendo massivamente é a classe trabalhadora, pois o vírus não impacta igualmente todos e todas. Podemos dizer sem riscos que a população negra (pretos e pardos, segundo o IBGE) vem sendo mais atingida. A falta de testagem segura também é um sintoma de como a pandemia está sendo abordada no país, dificultando intencionalmente que tenhamos uma dimensão mais precisa da propagação do vírus e de sua letalidade.

A dificuldade dos contrapesos ao arbítrio e posturas antidemocráticas do executivo, pelas demais instituições conforme a Constituição de 1988, e a fragmentação política após o golpe de novo tipo de 2016, também corroboram para o curso caótico e funesto dos acontecimentos. Após subscrever o golpe de 2016 e sob ataque das hostes bolsonaristas, o Congresso e o STF têm sido lenientes, com poucos momentos de exceção. Basta observar que existem inúmeros crimes de responsabilidade denunciados por pedidos de impeachment e que não tem solução de continuidade. Notícias da grande imprensa informam que cada deputado pode estar recebendo uma espécie de "carimbo" de cerca de 10 milhões em recursos que deveriam ir para a saúde pública, depois que se abriram os cofres para a calamidade pública. Assim, os recursos chegam na ponta como conquista do deputado/senador fulano ou sicrano, no mais puro clientelismo político. Aliás, o pior das tradições políticas brasileiras têm aparecido nesse momento dramático: superfaturamento de respiradores, de Equipamentos de Proteção Individual, de montagem de hospitais de campanha, na lógica de tirar vantagem de tudo. E vem à tona também um individualismo exacerbado por anos de neoliberalismo, do não cultivo de qualquer consciência do que é comum e público. Resta o enorme desafio para a construção das resistências, com o que pretende contribuir a investigação e reflexão aqui sistematizadas.

\section{REFERÊNCIAS}

BEHRING, E. R. Brasil em contrarreforma - Desestruturação do Estado e Perda de Direitos. São Paulo: Cortez, 2003. 
. Ajuste fiscal permanente e contrarreformas no Brasil da redemocratização. In: Crise do Capital e Fundo público: implicações para o trabalho, os direitos e a política social. p. 43-65. São Paulo: Cortez, 2019.

. Fundo Público, Valor e Política Social. São Paulo: Cortez Editora, 2020. No prelo.

BEHRING, E.; BOSCHETTI, I. "Transferência de renda", teto de gastos e oportunismo: para uma crítica de esquerda. In: Esquerda online, [s. 1.], 18 ago. 2020. Disponível em: https:/ / esquerdaonline.com.br/ 2020/08/18/transferencia-de-renda-teto-de-gastos-e-oportunismo-parauma-critica-de-esquerda/ Acesso em: set. 2020.

BEHRING; E. R., BOSCHETTI; I., GRANEMANN, S. (Orgs). Financeirização, Fundo Público e Política Social. São Paulo: Cortez, 2012.

BOSCHETTI, I.; TEIXEIRA, S. O. O draconiano ajuste fiscal do Brasil e a expropriação de direitos da seguridade social. In: SALVADOR, E.; BEHRING, E. R.; LIMA, R. de L. (Orgs.) Crise do Capital e Fundo Público - implicações para o trabalho, os direitos e a política social. p. 67 - 97. São Paulo: Cortez Editora, 2019.

BOSCHET'TI, I. (Org.). Expropriação e Direitos no Capitalismo. São Paulo: Cortez Editora, 2018.

CARVALHO, L. 10 Perguntas e respostas sobre a PEC 241 (EC 95). Blog da Boitempo,13/10/2016. Disponível em: < https://blogdaboitempo.com.br/2016/10/13/10-perguntas-e-respostas-sobre-a-pec241/>. Acesso em: 15 out. 2016.

CISLAGHI, J. F. Do neoliberalismo de cooptação ao ultraneoliberalismo: respostas do capital à crise. Esquerda on line. 08/06/2020. Disponível em:_<https://esquerdaonline.com.br/2020/06/08/do-neolibera- 
lismo-de-cooptacao-ao-ultraneoliberalismo-respostas-do-capital-acrise/>. Acesso em: set. 2020

CISLAGHI, J. F.; DEMIER, F. (Orgs.) O Neofascismo no Poder (Ano I) - Análises Críticas sobre o Governo Bolsonaro. Rio de Janeiro: Consequência, 2019.

DARDOT, P.; LAVAL, C. A nova razão do mundo: ensaio sobre a sociedade neoliberal. São Paulo: Editora Boitempo, 2016.

DEMIER, F. Depois do Golpe: a dialética da democracia blindada no Brasil. Rio de Janeiro: Ed. Mauad, 2017.

DIÁRIO OFICIAL DA UNIÃO. Seção 1 Emenda Constitucional No 95, - 16/12/2016, Página 2 . Disponível em: <http://www.planalto.gov.br/ccivil_03/constituicao/emendas/emc/emc95.htm>. Acesso em: set. 2020 .

FONTES, V. O Brasil e o Capital Imperialismo - teoria e história. Rio de Janeiro: FIOCRUZ- EPSJV e UFRJ, 2010.

HUSSON, M. Capitalismo al filo de la navaja. Bruxelas: CADTM, 2020. Disponível em:<https://www.cadtm.org/Capitalismo-al-filo-de-lanavaja $>$. Acesso em: set. 2020. .

LUCE, M. S. Teoria Marxista da Dependência - problemas e categorias. Uma visão histórica. São Paulo: Expressão Popular, 2018.

MANDEL, E. O Capitalismo Tardio. São Paulo: Col. Os Economistas, Abril Cultural, 1972/1982.

MARINI, R. M. Dialética da Dependência. São Paulo: Expressão Popular, 1973/2005. 
MATTOS, M. B. Governo Bolsonaro - neofascismo e autocracia burguesa no Brasil. São Paulo: Usina Editorial, 2020.

PDR. Plano Diretor da Reforma do Estado. Brasília: Presidência da República, Câmara da Reforma do Estado, Ministério da Administração Federal e Reforma do Estado. 1995. Disponível em: <http://www.biblioteca.presidencia.gov.br/publicacoes-oficiais/catalogo/fhc/plano-diretorda-reforma-do-aparelho-do-estado-1995.pdf>. Acesso em: 21 nov. 2020

\section{SALVADOR, E. Fundo Público e Seguridade Social no Brasil. São} Paulo: Cortez, 2010.

SENADO FEDERAL. Siga Brasil: Painel Especialista. Disponível em: $<$ https://www12.senado.leg.br/orcamento/sigabrasil>. Acesso em: 21 nov. 2020.

SOUZA, G. Transferência de renda e monetarização das políticas sociais: estratégia de captura do fundo público pelo capital portador de juros. In: SALVADOR, E. et. al. (orgs.). Financeirização, Fundo Público e Política Social. p. 209-240. São Paulo: Cortez, 2012. 